\title{
Burnout and work satisfaction in general practitioners practicing in rural areas: results from the HaMEdSi study
}

This article was published in the following Dove Press journal:

Psychology Research and Behavior Management

\author{
Charles Christian \\ Adarkwah ${ }^{1-3, *}$ \\ Annette Schwaffertz ${ }^{1,4, *}$ \\ Joachim Labenz ${ }^{5}$ \\ Annette Becker' \\ Oliver Hirsch ${ }^{6}$ \\ 'Department of General Practice and \\ Family Medicine, Philipps-University, \\ Marburg, Germany; ${ }^{2}$ Department of \\ Health Services Research, CAPHRI \\ School for Public Health and \\ Primary Care, Maastricht University, \\ Maastricht, the Netherlands; \\ ${ }^{3}$ Department of Health Services \\ Research and General Practice, \\ Faculty of Life Sciences, University of \\ Siegen, Siegen, Germany; ${ }^{4}$ University \\ of Giessen, Medical School, Giessen, \\ Germany; ${ }^{5}$ Diakonie Klinikum Siegen, \\ Department of Medicine, Siegen, \\ Germany; ${ }^{6}$ FOM University of Applied \\ Sciences, Siegen, Germany \\ *These authors contributed equally to \\ this work
}

Correspondence: Oliver Hirsch FOM University of Applied Sciences, Birlenbacher Straße 17, 57078 Siegen, Germany

Tel +49 27I 770032613

Fax +49646 49। I73।

Email oliver.hirsch@fom.de
Background: An increasing number of general practitioners (GPs) are not satisfied with their working conditions and are at risk of developing burnout symptoms. As family medicine is becoming a major subject within the medical curriculum in Germany, practicing GPs need to meet higher demands in the future, ie, treating patients and taking part in the education of medical students. Accordingly, we aimed to determine GPs' work satisfaction and risk of burnout.

Materials and methods: A survey was conducted among GPs in the region of SiegenWittgenstein. This area is a representative rural region in Germany. The Maslach Burnout Inventory (MBI) was used to assess the risk of burnout, while the Work Satisfaction Questionnaire (WSQ) was applied to assess work satisfaction. Canonical correlations were used to examine the association between work satisfaction and burnout in GPs.

Results: A good model fit was demonstrated for both the MBI and the WSQ. The canonical correlation analysis resulted in two statistically significant canonical functions with correlations of $0.64(P<0.001)$ and $0.56(P=0.001)$. The full model across all functions was significant $\left(\chi^{2}\right.$ $[18]=72.41, P<0.001)$. Burden and the global item in the WSQ are good predictors of emotional exhaustion, while patient care, personal rewards and professional relations seem to be good predictors of depersonalization/lack of empathy. This supports the approach to burnout as a multidimensional construct which has to be thoroughly diagnosed.

Conclusion: Differential interventions tailored to GPs with specific deficits in certain areas should be delivered. GPs with a high score on emotional exhaustion would need a different intervention, as these respondents have different associations with work satisfaction than do GPs with a high score for depersonalization/low empathy. Therefore, the results of this study could contribute to the design of differential interventions aimed at ameliorating symptoms of burnout in GPs.

Keywords: work satisfaction, burnout risk, GP, rural area

\section{Background}

Studies show that up to $50 \%$ of general practitioners (GPs) in Germany are not satisfied with their working conditions. ${ }^{1,2}$ Low work satisfaction with high stress levels and an unsatisfactory work-life balance can lead to symptoms of burnout. ${ }^{3}$ Whether or not a GP is likely to develop burnout symptoms depends on a number of factors, such as the amount of stress experienced while doing his or her job. ${ }^{4,5}$ Job stress is closely related to work satisfaction. ${ }^{6}$ In turn, the amount of pleasure one feels doing one's job, or work satisfaction, is determined by a number of factors. In comparison with other countries such as the USA or the UK, German GPs seem to have higher stress levels at work. ${ }^{7}$ European studies show that GPs in rural areas seem to be more 
affected by burnout symptoms. ${ }^{3,8}$ This is important, as the "Masterplan for Medical Education 2020" is a chance as well as a challenge for GPs. With this master plan, the importance of "general practice/family medicine" will significantly increase, as it will become a major subject within the medical education curriculum. ${ }^{9}$ Every student will have to complete 3 months of general practice education within the sixth study year (the practical year), and general practice will become a mandatory examination subject in the final oral examination (third part of the examination). A large number of GP practices for teaching and training will be necessary to comply with this demand. This means that GPs need to meet higher demands in the future, ie, not only treating an increasing number of patients but also actively taking part in the education of medical students.

In Siegen, where our survey took place, medical students will be educated and trained in the near future, as a new medical campus is being established in cooperation with the University of Bonn Medical School. In the rural district of Siegen-Wittgenstein, a shortage of doctors, especially GPs, is obvious and will dramatically increase in the near future, which might increase the abovementioned problem of work satisfaction and risk of burnout.

The aim of this study was to investigate the work satisfaction and burnout risk of GPs in the district of SiegenWittgenstein, a representative rural area in Germany, and to examine the relationship between structural characteristics of the GP practices and the GPs' work satisfaction and risk of burnout.

\section{Materials and methods Design and GP recruitment}

We conducted a study in which all GPs in the district of Siegen-Wittgenstein were invited to take part. Contact details of GPs were obtained by the Association of Statutory Health Insurance Physicians (Kassenärztliche Vereinigung WestfalenLippe [KVWL]). GPs were queried about their work satisfaction and risk of burnout. Furthermore, they were asked about their motivation for taking part in the medical education of students as well as their work perspective. In this paper, we focus on the GPs' work satisfaction and risk of burnout.

This survey (HaMEdSi: Hausärzte [GPs] for medical education in Siegen-Wittgenstein) was performed in general practices in the area of Siegen-Wittgenstein in Germany between October 2017 and January 2018. GPs were sent a written invitation with a detailed study description, an informed consent form and the study questionnaire. All instruments were administered in German. After 4 weeks, all
GPs who had not responded received a telephone reminder from a member of the study team. An invitation to participate was also sent by e-mail to all members of the local doctor's association, in which most of the GPs held a membership.

The study was performed in accordance with the Declaration of Helsinki and approved by the research ethics committee of the University of Marburg (Az.: Studie 127/17).

\section{Assessment of work satisfaction and risk of burnout}

The Work Satisfaction Questionnaire (WSQ) is composed of 17 items to be scored on a 7-point scale from " 1 - very dissatisfied" to " 7 - very satisfied". ${ }^{10,11}$ The questionnaire is based on the main components of work satisfaction identified by prior qualitative research conducted by the Society of General Internal Medicine Career Satisfaction Study Group. ${ }^{12}$ The items address satisfaction with relationships with patients, peers, nurses and other nonmedical staff, time for family, friends or leisure, workload and work stress, administrative burden, autonomy in treating patients, autonomy to refer patients to a specialist, intellectual stimulation at work, continuing medical education opportunities, enjoyment of work, respect and prestige, type of payment mechanism, current income, overall quality of care and job satisfaction in general. It has a five-factor structure, composed of patient care (four items, Cronbach's $\alpha=0.76$ ), burden (four items, $\alpha=0.79$ ), income-prestige (three items, $\alpha=0.83$ ), personal rewards (three items, $\alpha=0.71$ ) and professional relations (two items, $\alpha=0.66$ ). Furthermore, a global item asks for the respondent's satisfaction with their current job situation. This item correlates with the subscale scores from 0.39 to $0.71 .{ }^{10}$ The instrument was shown to be sensitive to structural changes in health care systems. ${ }^{13}$

We used the German version of the Maslach Burnout Inventory $(\mathrm{MBI})$ to assess occupational burnout. The MBI is designed to measure an enduring state of experiencing burnout, an assumption that is borne out by the stability of its scores over time. ${ }^{14}$ The MBI is composed of 22 items, each scored on a 7-point scale from " 0 - never" to "7 - every day". It consists of three subscales, namely "emotional exhaustion" (nine items), which measures exhaustion at work, depersonalization (five items), which measures emotional distance to others and loss of empathy, and personal accomplishment (eight items), which measures competence and a positive attitude toward work. The three-factor structure was confirmed; Cronbach's $\alpha$ of the emotional exhaustion scale was 0.85 , of the personal accomplishment subscale 0.71 , and of the depersonalization subscale was just $0.48 .{ }^{15}$ Other studies 
found higher internal consistencies for this subscale with Cronbach's $\alpha$ of 0.69 and 0.86 , respectively. ${ }^{16,17}$ Convergent and discriminant validity of the MBI could be demonstrated.

\section{Statistical analyses}

There were a maximum of five missing values on single items of the MBI and the WSQ. These were replaced by the k-nearest neighbor algorithm $(\mathrm{kNN})^{18}$ using the R package VIM.

We conducted confirmatory factor analysis with the $\mathrm{R}$ package lavaan ${ }^{19}$ to examine the hypothesized factorial structures of the MBI and the WSQ in our GP sample. We used the robust unweighted least squares estimator with robust standard errors and a mean- and variance adjusted test statistic (ULSMV), as this estimation method makes no distributional assumptions. ${ }^{19,20}$ Different model fit statistics were calculated. The $\chi^{2} / \mathrm{df}$ ratio is a badness-of-fit-index as smaller values indicate a better fit. ${ }^{21}$ Values around 2 signal a good model fit. The root mean square error of approximation (RMSEA) is a population-based index that relies on the noncentral $\chi^{2}$ distribution. It can be regarded as an "error of approximation" index, because it assesses the extent to which a model fits reasonably well in the population..$^{22}$ Values $\leq 0.08$ are considered to indicate an adequate model fit. ${ }^{23}$ The standardized root mean square residual (SRMR) was calculated to measure the mean absolute value of covariance residuals. ${ }^{24}$ Values below 0.10 indicate a good model fit. ${ }^{25}$ The Comparative Fit Index (CFI) and the Tucker Lewis Index (TLI) were not considered as they are sensitive to smaller sample sizes (like ours) in ULS estimation (the general estimation method in which we use a robust estimator). ${ }^{20}$ The resulting items and scales were examined by parameters based on classical test theory such as Cronbach's $\alpha$, discriminatory power and average intercorrelations. Omega coefficients for the applied scales were also computed using R packages such as psych and GPArotation as they have known advantages over Cronbach's $\alpha{ }^{26}$

We used Hotelling's $T^{2}$ test from the R library "Hotelling" to compare different demographic groups on the scales of the MBI and the WSQ. ${ }^{27}$ The effect size Mahalanobis distance $\left(D^{2}\right)$ measured the size of the multivariate effect. A value of .25 represents a small effect, .50 shows a medium and a value $>1$ demonstrates a large effect. ${ }^{28}$

We used canonical correlation analysis to examine the association between work satisfaction and burnout in GPs in Siegen-Wittgenstein. ${ }^{27}$ According to previous findings, we labeled the five scales and the overall item of the WSQ as independent variables and the three scales of the MBI as dependent variables. The subject to variable ratio was 9-1 and therefore close to the recommended $10-1$ ratio. ${ }^{29} \mathrm{We}$ also performed canonical commonality analysis to enhance the interpretation of the results. ${ }^{30}$

We used Spearman's correlation coefficient to calculate the associations between the MBI and Work Satisfaction subscales and other variables, as most of the attributes deviated significantly from the normal distribution. ${ }^{31}$ Due to multiple testing, the significance value was adjusted by the Bonferroni correction. ${ }^{32}$

\section{Results \\ Characterization of the study sample}

The total population consisted of 158 GPs. Of these, 85 $(53.8 \%)$ took part in the study and completed the questionnaire. There were 64 male GPs $(75.3 \%)$ in our sample. The gender distribution conformed to the proportions in the population in this specific area. The mean age of the participants was 53.5 years (SD 8.93), with a median age of 54 years, a minimum age of 32 years and a maximum age of 73 years. The majority $(91.8 \%)$ were practice owners, worked full time (90.6\%) and worked in a group practice $(67.1 \%)$. The average study participant had worked in private practice for 18.41 years (mean, SD 9.8 years) with a range between 2 and 43 years. Most of them were specialized in general practice $(51.8 \%)$, whereas $24.7 \%$ were specialized in internal medicine and $20.0 \%$ had both specializations. The minority $(3.5 \%)$ were medical practitioner without any further specialization. This denomination was disestablished and taken out the regulation for further education in 1992. It is noteworthy that despite all of a higher level of bureaucracy and an increasing number of patients, 94\% of the respondents would choose to become a GP again. The distribution regarding the place of the practice in our sample also corresponded to the population in this area. For example, the proportion of primary care physicians practicing in Siegen in our sample was the same as in the whole population. Therefore, our sample can be regarded as representative. Table 1 summarizes the demographic characteristics of the study participants.

\section{Burnout}

\section{Methodological evaluation of the MBI}

We tested the hypothesized three-factor structure in our GP sample. The confirmatory factor analysis with the robust ULSMV estimation method showed a good model fit: $\chi^{2} /$ $\mathrm{df}=1.16$, RMSEA $=0.044, \mathrm{SRMR}=0.092$.

Four items have factor loadings under the recommended cutoff value of $0.30 .^{22}$ Detailed information on factor loadings in our sample is summarized in Table S1. 
Table I Demographic characteristics of study participants $(n=85)$

\begin{tabular}{|c|c|}
\hline \multicolumn{2}{|l|}{ General characteristics } \\
\hline \multirow[t]{2}{*}{ Gender } & $75 \%$ male \\
\hline & $25 \%$ female \\
\hline \multirow[t]{2}{*}{ Practice ownership } & $92 \%$ practice owners \\
\hline & $8 \%$ practice employees \\
\hline \multirow[t]{4}{*}{ Specialization } & $52 \%$ general practice \\
\hline & $25 \%$ internal medicine \\
\hline & $20 \%$ general practice and internal medicine \\
\hline & $3 \%$ none \\
\hline \multirow[t]{2}{*}{ Practice size } & $33 \%$ single practice \\
\hline & $67 \%$ group practice \\
\hline \multirow[t]{2}{*}{ Modus of work } & $91 \%$ full time \\
\hline & $9 \%$ part time \\
\hline \multirow[t]{2}{*}{ Would become GP again } & $94 \%$ yes \\
\hline & $6 \%$ no \\
\hline \multicolumn{2}{|l|}{ Qualification of nonmedical staff } \\
\hline \multirow[t]{2}{*}{ Practice nurse } & $39 \%$ yes \\
\hline & $61 \%$ no \\
\hline \multirow[t]{3}{*}{ Number of practice nurses } & $77 \% 1$ \\
\hline & $16 \% 2$ \\
\hline & $7 \% 4$ \\
\hline \multirow[t]{2}{*}{ Staff member currently doing the practice nurse curriculum } & II\% yes \\
\hline & $89 \%$ no \\
\hline \multirow[t]{2}{*}{ Number of staff members currently doing the practice nurse curriculum } & $56 \% 1$ \\
\hline & $44 \% 2$ \\
\hline \multirow[t]{2}{*}{ Staff member planning to do the curriculum } & $35 \%$ yes \\
\hline & $65 \%$ no \\
\hline
\end{tabular}

Abbreviation: GP, general practitioner.

Intercorrelations of factors are satisfactory with emotional exhaustion correlating with depersonalization/loss of empathy by $r=0.69$ and with personal accomplishment by $r=-0.43$, while depersonalization/loss of empathy correlates with personal accomplishment by $r=-0.55$.

The Cronbach's $\alpha$ coefficient of the emotional exhaustion subscale was 0.84 , the omega coefficient was 0.85 and the average inter-item correlation was 0.38 . The discriminatory power of the items ranged from 0.32 to 0.76 . The Cronbach's $\alpha$ coefficient of the depersonalization/loss of empathy subscale was 0.69 , the omega coefficient was 0.71 and the average inter-item correlation was 0.31 . The discriminatory power of the items ranged from 0.34 to 0.59 . The Cronbach's $\alpha$ coefficient of the personal accomplishment subscale was 0.70 , the omega coefficient was 0.71 and the average interitem correlation was 0.23 . The discriminatory power of the items ranged from 0.25 to 0.54 . All values can be classified as satisfactory to high.

The main characteristics of the MBI subscales in our sample are summarized in Table 2.

The subscales such as emotional exhaustion and depersonalization/loss of empathy deviated significantly from a normal distribution, while the distribution of personal accomplishment mainly corresponded to a normal distribution. According to normative values as per the study by Soler et al, ${ }^{33} 42$ physicians (49.4\%) had a low level of emotional exhaustion, $33(38.8 \%)$ had an average level and ten (11.8\%) reported a high level of emotional exhaustion. According to normative values as per the study by Soler et al, ${ }^{33} 59$ physicians (69.4\%) had a low level of depersonalization/loss of empathy, 15 (17.7\%) had an average level and eleven (12.9\%) reported a high level of depersonalization/loss of empathy. According to normative values as per the study by Soler et al, ${ }^{33} 37$ physicians $(43.5 \%)$ had a high sense of personal accomplishment, $26(30.6 \%)$ had an average level and $22(25.9 \%)$ reported a low level of personal accomplishment. The reliability values of the MBI subscales can be classified as satisfactory to high.

\section{Associations between burnout and demographic characteristics}

We median dichotomized the quantitative variable age and compared the younger GPs with the older GPs on the three subscales of the MBI. There was no significant difference between the two groups: $T^{2}(3,80)=3.51, P=0.34$. The effect 
Table 2 Main characteristics of the MBI subscales in the study sample $(n=85)$

\begin{tabular}{|c|c|c|c|}
\hline MBI subscale & Descriptives & Normality & Reliability \\
\hline Emotional exhaustion & $\begin{array}{l}\text { Mean } 15.5 \\
\text { SD } 8.9 \\
\text { Median } 14 \\
\text { Range: } 2-40\end{array}$ & $\begin{array}{l}\text { Shapiro-Wilk test: } P=0.002 \\
\text { Skewness: } P=0.006 \\
\text { Kurtosis: } P=0.36\end{array}$ & $\begin{array}{l}\text { Cronbach's } \alpha: 0.84 \\
\Omega=0.85 \\
\text { Average } r: 0.38 \\
\text { Discriminatory power: } 0.32-0.76\end{array}$ \\
\hline Depersonalization/loss of empathy & $\begin{array}{l}\text { Mean } 4.5 \\
\text { SD } 4.5 \\
\text { Huber M: } 3.7 \\
\text { Median } 3 \\
\text { Range: } 0-19\end{array}$ & $\begin{array}{l}\text { Shapiro-Wilk test: } P<0.00 \text { I } \\
\text { Skewness: } P<0.00 \text { I } \\
\text { Kurtosis: } P=0.008\end{array}$ & $\begin{array}{l}\text { Cronbach's } \alpha: 0.69 \\
\Omega=0.7 \mid \\
\text { Average } r: 0.31 \\
\text { Discriminatory power: } 0.34-0.59\end{array}$ \\
\hline Personal accomplishment & $\begin{array}{l}\text { Mean } 37.7 \\
\text { SD } 5.8 \\
\text { Median } 38 \\
\text { Range: } 19-48\end{array}$ & $\begin{array}{l}\text { Shapiro-Wilk test: } P=0.06 \\
\text { Skewness: } P=0.07 \\
\text { Kurtosis: } P=0.49\end{array}$ & $\begin{array}{l}\text { Cronbach's } \alpha: 0.70 \\
\Omega=0.7 \text { I } \\
\text { Average } r: 0.23 \\
\text { Discriminatory power: } 0.25-0.54\end{array}$ \\
\hline
\end{tabular}

Note: Average $r$, average inter-item correlation; $\Omega$, omega coefficient.

Abbreviation: $\mathrm{MBI}$, Maslach Burnout Inventory.

size $D^{2}$ revealed a small effect with $0.17 . .^{28}$ The difference between male and female GPs missed significance: $T^{2}$ $(3,81)=7.01, P=0.09$, but the effect size $D^{2}$ showed almost a medium effect of 0.44 . Female physicians had a slightly higher level of emotional exhaustion (17.1, SD 9.0) than did their male colleagues (14.9, SD 8.8).

The number of years practicing was also median dichotomized, and we then compared those GPs who had been practicing longer with those who had started practicing recently regarding their scores on the MBI. We found no significant differences between the two groups: $T^{2}(3,75)=2.06, P=0.57$, and the effect size $D^{2}$ showed a negligible effect with 0.10 .

GPs in group practices were not significantly different in their MBI scores in comparison with those in single practices: $T^{2}(3,78)=1.09, P=0.78, D^{2}=0.06$. GPs whose practices will continue after their retirement were not significantly different in their MBI scores in comparison with those whose practices will most likely be closed when they retire: $T^{2}(3,75)=5.29$, $P=0.17, D^{2}=0.35$. The estimated probability of the practice continuing under a colleague after own retirement correlated significantly with personal accomplishment (Spearman's $r=0.34, P=0.002$ ). The estimated probability of getting a reimbursement for the practice when retiring correlated significantly with personal accomplishment (Spearman's $r=0.38, P=0.001$ ). Other correlations, eg, number of working hours and percentage of patient contact, showed no significant associations with the scales of the MBI.

\section{Work satisfaction}

\section{Methodological evaluation of the WSQ}

We tested the hypothesized five-factor structure in our GP sample. The confirmatory factor analysis with the robust
ULSMV estimation method showed a good model fit: $\chi^{2} /$ $\mathrm{df}=1.47, \mathrm{RMSEA}=0.075, \mathrm{SRMR}=0.095$.

All items have factor loadings over the recommended cutoff value of $0.30 .{ }^{22}$ Detailed information on factor loadings in our sample is summarized in Table S2.

Intercorrelations of factors were satisfactory. The lowest correlation occurred between patient care and burden, with $r=0.18$, and the highest between patient care and professional relations, with $r=0.72$. Detailed information on factor intercorrelations in our sample is summarized in Table S3.

The main characteristics of the subscales of the WSQ in our sample are summarized in Table 3.

Professional relations deviated significantly from normality, while the other subscales mainly corresponded to a normal distribution. Reliability coefficients except for income-prestige and professional relations were satisfactory. The means in our sample were approximately in the range of those reported by Bovier and Perneger. ${ }^{10}$

\section{Associations between work satisfaction and demographic characteristics}

Male and female GPs did not differ significantly regarding their scores on the scales of the WSQ or for the global item: $T^{2}(6,78)=9.45, P=0.20, D^{2}=0.60$. The effect size $D^{2}$ signals a medium effect which is mainly due to the male patients scoring higher in patient care -22.1 (SD 3.7) vs 20.2 (SD 3.6) for female physicians. The two age groups did not differ significantly regarding their scores on the scales of the WSQ or for the global item: $T^{2}(6,77)=7.57, P=0.32, D^{2}=0.36$. The number of years in practice also had no significant association with Work Satisfaction: $T^{2}(6,72)=8.72, P=0.24, D^{2}=0.44$. 
Table 3 Main characteristics of the WSQ subscales in the study sample $(n=85)$

\begin{tabular}{|c|c|c|c|}
\hline WSQ subscale & Descriptives & Normality & Reliability \\
\hline Patient care & $\begin{array}{l}\text { Mean } 21.7 \\
\text { SD } 3.7 \\
\text { Median } 22 \\
\text { Range: } 13-28 \\
\end{array}$ & $\begin{array}{l}\text { Shapiro-Wilk test: } P=0.04 \\
\text { Skewness: } P=0.4 \mathrm{I} \\
\text { Kurtosis: } P=0.07\end{array}$ & $\begin{array}{l}\text { Cronbach's } \alpha: 0.78 \\
\Omega=0.79 \\
\text { Average } r: 0.46 \\
\text { Discriminatory power: } 0.48-0.66\end{array}$ \\
\hline Burden & $\begin{array}{l}\text { Mean } 16.4 \\
\text { SD } 4.5 \\
\text { Median } 16 \\
\text { Range: } 7-28 \\
\end{array}$ & $\begin{array}{l}\text { Shapiro-Wilk test: } P=0.28 \\
\text { Skewness: } P=0.40 \\
\text { Kurtosis: } P=0.21\end{array}$ & $\begin{array}{l}\text { Cronbach's } \alpha: 0.76 \\
\Omega=0.77 \\
\text { Average } r: 0.44 \\
\text { Discriminatory power: } 0.40-0.68\end{array}$ \\
\hline Income-prestige & $\begin{array}{l}\text { Mean I5.4 } \\
\text { SD } 2.7 \\
\text { Median } 16 \\
\text { Range: } 9-2 \text { I }\end{array}$ & $\begin{array}{l}\text { Shapiro-Wilk test: } P=0.08 \\
\text { Skewness: } P=0.25 \\
\text { Kurtosis: } P=0.50\end{array}$ & $\begin{array}{l}\text { Cronbach's } \alpha: 0.58 \\
\Omega=0.62 \\
\text { Average } r: 0.31 \\
\text { Discriminatory power: } 0.23-0.53\end{array}$ \\
\hline Personal rewards & $\begin{array}{l}\text { Mean } 17.0 \\
\text { SD } 2.6 \\
\text { Median } 17 \\
\text { Range: } 9-21 \\
\end{array}$ & $\begin{array}{l}\text { Shapiro-Wilk test: } P=0.007 \\
\text { Skewness: } P=0.10 \\
\text { Kurtosis: } P=0.11\end{array}$ & $\begin{array}{l}\text { Cronbach's } \alpha: 0.70 \\
\Omega=0.7 \text { I } \\
\text { Average } r: 0.43 \\
\text { Discriminatory power: } 0.44-0.58\end{array}$ \\
\hline Professional relations & $\begin{array}{l}\text { Mean II.3 } \\
\text { SD } 1.9 \\
\text { Median II } \\
\text { Range: } 5-14\end{array}$ & $\begin{array}{l}\text { Shapiro-Wilk test: } P<0.00 \text { I } \\
\text { Skewness: } P=0.006 \\
\text { Kurtosis: } P=0.16\end{array}$ & $\begin{array}{l}\text { Cronbach's } \alpha: 0.65 \\
\Omega=0.65 \\
\text { Item } r: 0.48\end{array}$ \\
\hline
\end{tabular}

Note: Average $r$, average inter-item correlation; $\Omega$, omega coefficient.

Abbreviation: WSQ, Work Satisfaction Questionnaire.

There are no significant differences regarding Work Satisfaction between GPs in group practices and those working in single practices: $T^{2}(6,75)=2.90, P=0.84, D^{2}=0.16$. GPs whose practices will continue after their retirement under another physician did not score significantly differently in their Work Satisfaction in comparison with those whose practices will be closed when they retire: $T^{2}(6,72)=5.42$, $P=0.54, D^{2}=0.36$. There was a significant negative correlation between the burden subscale score and the number of working hours per week $(r=-0.33, P=0.002)$. All other variables (possible reimbursement, percentage of patient contacts and administrative tasks as measured by the total number of working hours per week) correlated $<0.30$ with the scales of the WSQ and the global item and were not significant after Bonferroni correction.

\section{Association between burnout and work satisfaction}

The canonical correlation analysis resulted in three canonical functions with canonical correlations of $0.64(P<0.001)$, $0.56(P=0.001)$ and $0.14(P=0.81)$. The full model across all functions was significant $\left(\chi^{2}[18]=72.41, P<0.001\right) .{ }^{30}$ The first two functions are statistically significant and each accounts for a considerable amount of variance $(41 \%$ and $31 \%$, respectively), although interpreting squared multiple correlations as indicating the amount of shared variance between two variable sets have been criticized. ${ }^{34}$ The often-used redundancy index has also been criticized for being simply the average squared multiple correlations from predicting the variables in one set from the variables in the other set. Cramer and Nicewande ${ }^{35}$ proposed the average squared multiple correlations as the measure of variance accounted for. In our case, this would result in a shared variance of $25 \%$.

Function 1 revealed that the predictor canonical variate is characterized by burden and the global item regarding the job situation in general, which explain $96 \%$ of the variance of this variate. The first criterion canonical variate is characterized mainly by emotional exhaustion $(r=0.91)$, which explains $84 \%$ of the variance of this variate (Table S4). Burden and the global item regarding the job situation seem to be good predictors of emotional exhaustion. The relatively high standardized function coefficients for income-prestige and professional relations and their low correlations with the first canonical variate indicate the presence of a suppression effect. The low standardized function coefficient of care and the relatively high correlation with the first canonical variate indicate that the variance of this variable is explained by another variable (Table 4).

With commonality analysis it is possible to partition the variance which each variable contributes to the explained 
variance expressed by the squared canonical correlation of each canonical function into unique variance and into common variance, which is variance contributed by a combination of several variables. ${ }^{30}$ In function 1 , the canonical variate for burnout was explained primarily by variance unique to the global item on job satisfaction. The squared canonical correlation was 0.406 , and the global item contributed 0.24 (59.4\% of the squared canonical correlation) to this squared coefficient. Next was variance common to burden and the global item on job satisfaction, with a coefficient of 0.10 (25.2\% of the squared canonical correlation), while the unique contribution of burden was just 0.02 (4.9\% of the squared canonical correlation; Table 5). The canonical variate for Work Satisfaction was primarily explained by exhaustion, with a coefficient of 0.35 (86.6\% of the squared canonical correlation).

Function 2 revealed that the predictor canonical variate is characterized by patient care, personal rewards and professional relations, which together explain more than 100\% of the variance of this variate. This means that some of the variance they account for is commonly explained by these three variables. The canonical variate of the first criterion is characterized mainly by depersonalization/lack of empathy $(r=0.97)$, which explains $95 \%$ of the variance of this variate (Table S5). Patient care, personal rewards and professional relations seem to be good predictors of depersonalization/ lack of empathy. The low standardized function coefficient of

Table 4 Standardized canonical coefficients and structure correlations of the first predictor canonical variate

\begin{tabular}{|l|l|l|}
\hline $\begin{array}{l}\text { Predictor } \\
\text { canonical variate }\end{array}$ & $\begin{array}{l}\text { Standardized } \\
\text { canonical coefficients }\end{array}$ & $\begin{array}{l}\text { Structure } \\
\text { correlations }\end{array}$ \\
\hline Patient care & -0.09 & -0.24 \\
Burden & -0.26 & -0.54 \\
Income-prestige & 0.38 & -0.09 \\
Personal rewards & 0.22 & -0.27 \\
Professional relations & 0.43 & -0.05 \\
Global item & -1.17 & -0.82 \\
\hline
\end{tabular}

Table 5 Main results of commonality analysis for the first predictor canonical variate

\begin{tabular}{lll}
\hline Predictor canonical variate & Coefficient & \% Total \\
\hline Unique to global item & 0.24 & 59.4 \\
Common to burden and global item & 0.10 & 25.2 \\
Unique to professional relations & 0.05 & 12.0 \\
Unique to income-prestige & 0.04 & 10.7 \\
Unique to burden & 0.02 & 4.9 \\
\hline
\end{tabular}

income-prestige and the relatively high correlation with the second canonical variate indicates that the variance of this variable is explained by another variable (Table 6).

In function 2 , the canonical variate of burnout with a squared canonical correlation of 0.313 was explained by several elements. The unique contribution of burden with a coefficient of 0.078 (25.0\% of the squared canonical correlation) was highest, followed by the unique contribution of the global item on job satisfaction: 0.043 (13.9\%) and the common contribution of patient care and professional relations: $0.04(12.8 \%)$. It is apparent that in the main patient care, personal rewards and professional relations contribute to the second canonical variate by common variance in combination with other variables (Table 7).

\section{Discussion}

Concerning the measurement of both aspects, work satisfaction and burnout, we could demonstrate good model fits in confirmatory factor analyses regarding our study population. This is important as the structure of questionnaires has to be examined in each special subpopulation before postulated subscores can be calculated. ${ }^{22}$

Table 6 Standardized canonical coefficients and structure correlations of the second predictor canonical variate

\begin{tabular}{lll}
\hline $\begin{array}{l}\text { Predictor } \\
\text { canonical variate }\end{array}$ & $\begin{array}{l}\text { Standardized } \\
\text { canonical coefficients }\end{array}$ & $\begin{array}{l}\text { Structure } \\
\text { correlations }\end{array}$ \\
\hline Patient care & -0.62 & -0.81 \\
Burden & -0.33 & -0.36 \\
Income-prestige & 0.06 & -0.21 \\
Personal rewards & -0.45 & -0.66 \\
Professional relations & -0.39 & -0.70 \\
Global item & 0.56 & -0.31 \\
\hline
\end{tabular}

Table 7 Main results of commonality analysis for the second predictor canonical variate

\begin{tabular}{|c|c|c|}
\hline Predictor canonical variate & Coefficient & \% Total \\
\hline Unique to patient care & 0.08 & 25.0 \\
\hline Unique to global item & 0.0434 & 13.9 \\
\hline Common to patient care and professional & 0.04 & 12.8 \\
\hline relations unique to personal rewards & 0.036 & 11.5 \\
\hline $\begin{array}{l}\text { Common to patient care and personal } \\
\text { rewards }\end{array}$ & 0.034 & 10.9 \\
\hline $\begin{array}{l}\text { Common to patient care, personal } \\
\text { rewards and professional relations }\end{array}$ & 0.033 & 10.5 \\
\hline Unique to professional relations & 0.031 & 9.8 \\
\hline $\begin{array}{l}\text { Common to care, personal relations and } \\
\text { global item }\end{array}$ & 0.018 & 5.7 \\
\hline
\end{tabular}


The three-factor structure of the MBI could be confirmed in our sample. Two items of the depersonalization/loss of empathy and personal accomplishment subscales had factor loadings of $<0.30$ and could therefore be eliminated in further analyses in this specific subgroup. The internal consistency of the exhaustion subscale was high, while the internal consistencies of the depersonalization/loss of empathy and personal accomplishment subscales were satisfactory. There were just two significant associations of the MBI subscale, personal accomplishment: with probability of the practice continuing under a colleague after the respondent's retirement and with the probability of receiving reimbursement for the practice after retiring. This might be interpreted in the way that GPs with higher scores in personal accomplishment are more selfconfident regarding their negotiating skills as it is not easy to find a follower for the practice because of the shortage of GPs in Germany. Furthermore, it is even more difficult to find a follower who is willing to pay a certain amount of money for the practice in such a situation. Burnout has been investigated in various studies; however, studies that include a population sample of GPs are few. Depersonalization/low empathy was reported to be higher in male GPs. ${ }^{36}$ Burnout was found in $19.4 \%$ of Dutch GPs when a combined criterion was used involving the upper $25 \%$ in comparison with normative data from health care workers. ${ }^{36}$ There was a relatively low rate of high burnout (3.7\%) in a Spanish sample. Age and gender were not associated with scores on the MBI. ${ }^{37}$ Rottenfußer ${ }^{38}$ reported that $27.7 \%$ of her sample of German physicians were at high risk for developing burnout, but that GPs were among the most satisfied. Taking care of themselves and delegating administrative tasks were among the most important measures for improving their situation. Long working hours, especially in surgeons, and in physicians early in their career were two aspects associated with higher burnout scores. ${ }^{39}$ Kirkcaldy et $\mathrm{al}^{40}$ found a correlation of 0.35 between stress and the number of working hours in a mixed sample of health care personnel, including physicians. High emotional exhaustion (37.9\%) and high depersonalization (29.4\%) were much more present in a mixed US physician sample, while there was a lower rate of low personal accomplishment (12.4\%). Family medicine was among the five disciplines with the highest burnout rates in the US sample, and younger age and longer working hours were associated with higher burnout risk. The burnout risk for physicians was higher than that of the general working population in the US. ${ }^{41}$

In our study sample, there were no large characteristic associations showing a high probability of developing a burnout. Female physicians had a slightly higher level of emotional exhaustion than did their male colleagues. This was not significant and represented a small effect. Nevertheless, this might be an area of further study as women were shown to have elevated scores on harm avoidance in the Temperament and Character Inventory. ${ }^{42}$ Harm avoidance is characterized by worrying, pessimism and being doubtful. Further studies might also use this specific scale to see whether female GPs have a certain vulnerability in this area. There is a large heterogeneity regarding all demographic characteristics. Even the number of working hours per week had no significant impact on the risk of burnout nor did the other demographic characteristics. Nevertheless, a remarkable proportion of our study sample reported a sense of low personal accomplishment (25.9\%). This is a cause for action, and further qualitative studies should investigate the reasons behind this. The proportion of physicians with a high sense of depersonalization was not higher than in other GP-related studies (12.9\%).

We could also confirm the five-factor structure of the WSQ. Internal consistencies were satisfactory and comparable with those of the original publications, ${ }^{10,13}$ except for the subscale "income-prestige" which has a Cronbach's $\alpha$ coefficient of 0.58 and an omega coefficient of 0.62 . The intercorrelations between the subscale scores also corresponded to those reported by the authors of the instrument. Consequently, work satisfaction must be regarded as a multidimensional construct which contains different aspects. A systematic review on job satisfaction in GPs has revealed that some factors in general increase job satisfaction, ie, variety within the job, relationships and contact with colleagues and teaching medical students, while other factors most likely reduce work satisfaction include income, working hours, administrative load, too much work, not enough time and not enough recognition. ${ }^{43}$ Primary care physicians in several European countries with longer professional experience were more satisfied with their job, but the effect was small. Furthermore, structural aspects were mainly associated with job satisfaction. ${ }^{44}$ Looking at the associations between work satisfaction and demographic characteristics of the study population, we could show a significant correlation between the burden subscale score and the number of working hours per week, which is quite intuitive. Surprisingly, work satisfaction in GPs working in a group practice or in a single practice did not differ significantly. One would expect higher work satisfaction in group practices, most likely due to sharing of work, teamwork and other positive aspects. On the other hand, working in a group practice can also have negative sides, as working in this way has higher potential for conflicts and may mean making compromises. All other variables did not have significant associations with the scales of the questionnaire. 
Canonical correlation analysis was used to examine the association between work satisfaction and burnout in primary care physicians in Siegen-Wittgenstein. The first canonical function revealed that burden and the global item on general job satisfaction were the best predictors of emotional exhaustion. The second canonical function showed that patient care, personal rewards and professional relations were good predictors of depersonalization/lack of empathy. Commonality analysis further showed that for the most part combinations of these variables predicted this aspect of burnout. This shows that this kind of analysis has an advantage over simple zero-order correlations, as interactions of specific variables can be taken into account. ${ }^{30}$ Our results corroborate several other findings. Interprofessional teamwork was shown to be a decisive factor for job satisfaction in health care..$^{45} \mathrm{In}$ the US, for family physicians employed by multi-specialty practices, social relationships were the strongest predictors of work satisfaction and commitment; eg, satisfaction with the practice was best predicted by relations with patients. The authors conclude that it is unlikely that one type of dissatisfaction will predict an outcome like burnout; rather this is a combination of several types. ${ }^{46}$

Bovier et a ${ }^{11}$ found an association between income-prestige and professional relations on the WSQ and emotional exhaustion on the MBI, while univariate associations in our sample were relatively low, at -0.13 and -0.25 , respectively. In contrast to earlier studies, ${ }^{10,11}$ we were not able to find substantial predictors of personal accomplishment. Zero-order correlations with subscales of the WSQ were in the range of $0.10-0.19$ and 0.28 with the global item.

A strength of our study is that we were able to conduct a full population survey in a limited geographic area. The response rate of $53.8 \%$ can be regarded as satisfactory and is comparable to other studies in the field. ${ }^{36,37}$ Furthermore, the survey contained several self-relevant questions regarding work satisfaction and risk of burnout. These are topics which might cause psychological irritation and might therefore be avoided. This might in turn result in rejecting participation in a survey containing questions having a possible negative influence on self-esteem. ${ }^{47}$

As a limitation, we have to mention that the sample size for confirmatory factor analysis was smaller than the $n=200$ proposed in the literature, ${ }^{22}$ although the resulting solutions had satisfactory quality criteria.

\section{Conclusion}

The investigation of the association between work satisfaction and burnout risk for GPs revealed interesting results, which have an important impact for clinical management. Burden and the global item in the WSQ are good predictors of emotional exhaustion, while patient care, personal rewards and professional relations seem to be good predictors of depersonalization/lack of empathy. This supports the approach of burnout being a multidimensional construct, which has to be thoroughly diagnosed. Hence, differential interventions tailored to those with specific deficits in certain areas should be delivered. As our results reveal, a GP with a high score on emotional exhaustion would need a different intervention, as there are different associations with work satisfaction than for a GP with a high score on depersonalization/low empathy. This can be represented by the model of Lee et al, ${ }^{39}$ which might be further operationalized. Lee et al proposed a traffic light model which could be used in an intervention to help GPs manage symptoms of burnout. At the red sign, they should stop and reliably measure symptoms of burnout, at the yellow sign, they should evaluate organizational, personal and patient factors that could be associated with symptoms of burnout, and at the green sign, they should target the three factors by getting support from medical organizations, balancing personal and work life and obtaining understanding from patients. The results of our study could contribute substantially to the design of various interventions aimed to ameliorate symptoms of burnout in GPs.

\section{Data sharing statement}

All study data and materials are available upon request.

\section{Acknowledgments}

We thank all the GPs who participated in this study. Our respondents offered their experience and insights without receiving financial compensation, and we are grateful.

\section{Disclosure}

The authors report no conflicts of interest in this work.

\section{References}

1. Behmann M, Schmiemann G, Lingner H, Kühne F, Hummers-Pradier E, Schneider N. Job satisfaction among primary care physicians: results of a survey. Dtsch Arztebl Int. 2012;109(11):193-200.

2. Schaefer H-M, Becker A, Krentz H, Harloff R. Rostocker Hausärzte im Visier - Vergleich der Berufszufriedenheit 2004 und 2006 [General Practitioners in focus - comparison of job satisfaction 2004 and 2006] Zeitschrift für Allgemeinmedizin. 2007;83:1-4.

3. Goehring C, Bouvier Gallacchi M, Künzi B, Bovier P. Psychosocial and professional characteristics of burnout in Swiss primary care practitioners: a cross-sectional survey. Swiss Med Wkly. 2005;135(7-8): 101-108.

4. Brill PL. The need for an operational definition of burnout. Fam Community Health. 1984;6(4):12-24. 
5. Cooper CL, Quick JC, Schabracq M, editors. International handbook of work and health psychology. 3rd ed. Chichester: Wiley-Blackwell; 2015.

6. Cooper CL, Rout U, Faragher B. Mental health, job satisfaction, and job stress among general practitioners. BMJ. 1989;298(6670):366-370.

7. Siegrist J, Shackelton R, Link C, Marceau L, von dem Knesebeck O, Mckinlay J. Work stress of primary care physicians in the US, UK and German health care systems. Soc Sci Med. 2010;71(2):298-304.

8. Fuchs S, Endler PC, Mesenholl E, Pass P, Frass M. Burnout bei niedergelassenen Arztinnen und Arzten für Allgemeinmedizin [Burnout in General Practitioners]. Wien Med Wochenschr. 2009;159(7-8):188-191.

9. Bundesministerium für Gesundheit. Masterplan Medizinstudium; 2020. Available from: https://www.bundesgesundheitsministerium.de/ ministerium/meldungen/2017/maerz/masterplan-medizinstudium-2020. html. Accessed April 18, 2018.

10. Bovier PA, Perneger TV. Predictors of work satisfaction among physicians. Eur J Public Health. 2003;13(4):299-305.

11. Bovier PA, Arigoni F, Schneider M, Gallacchi MB. Relationships between work satisfaction, emotional exhaustion and mental health among Swiss primary care physicians. Eur J Public Health. 2009;19(6):611-617.

12. Mcmurray JE, Williams E, Schwartz MD, et al. Physician job satisfaction: developing a model using qualitative data. SGIM Career Satisfaction Study Group. J Gen Intern Med. 1997;12(11):711-714.

13. Perneger TV, Deom M, Cullati S, Bovier PA. Growing discontent of Swiss doctors, 1998-2007. Eur J Public Health. 2012;22(4):478-483.

14. Maslach C, Jackson SE, Leiter MP. Maslach Burnout Inventory. Manual. 3rd ed. Mountain View, CA: Consulting Psychologists Press Inc. 1996.

15. Neubach B, Schmidt K-H. Gütekriterien einer deutschen Fassung des Maslach Burnout Inventory (MBI-D) - Eine Replikationsstudie bei Altenpflegekräften [Statistical quality criteria of a German version of the Maslach Burnout Inventory (MBI-D). A replication study with elderly care nurses]. Zeitschrift für Arbeits- und Organisationspsychologie $A \& O .2000 ; 44(3): 140-144$.

16. Schwarzer R, Schmitz GS, Tang C. Teacher burnout in Hong Kong and Germany: A cross-cultural validation of the Maslach Burnout Inventory. Anxiety Stress Coping. 2000;13:309-326.

17. Gumz A, Erices R, Brähler E, Zenger M, et al. Faktorstruktur und Gütekriterien der deutschen Übersetzung des Maslach-Burnout-Inventars für Studierende von Schaufeli, et al. MBI-SS. Psychother Psychosom Med Psychol. 2013;63(2):77-84.

18. Beretta L, Santaniello A. Nearest neighbor imputation algorithms: A critical evaluation. BMC Med Inform Decis Mak. 2016;16(Suppl 3):74.

19. Rosseel Y. lavaan: An R Package for Structural Equation Modeling. $J$. Stat Soft. 2012;48(2):1-36.

20. Lei PW, Wu Q. Estimation in structural equation modeling. In: Hoyle $\mathrm{RH}$, editor. Handbook of structural equation modeling. Paperback ed. New York (NY): Guilford Press; 2015:164-180.

21. West SG, Taylor AB, Wu W. Model fit and model selection in structural equation modeling. In: Hoyle RH, editor. Handbook of Structural Equation Modeling. Paperback ed. New York (NY): Guilford Press; 2015:209-231.

22. Brown TA. Confirmatory Factor Analysis for Applied Research. Methodology in the Social Sciences. 2nd ed. New York, London: The Guilford Press; 2015.

23. Browne KA, Cudeck JS. Alternative ways of assessing equation model fit. In: Bollen KA, editor. Testing Structural Equation Models. [Nachdr]. Newbury Park, CA: Sage; 1993:136-162.

24. Little TD, Kline RB, editors. Principles and Practice of Structural Equation Modeling Methodology in the Social Sciences. 4th ed. New York, London: The Guilford Press; 2016.

25. Weiber R, Mühlhaus D. Strukturgleichungsmodellierung [Structural equation modeling]: Eine anwendungsorientierte Einführung in die Kausalanalyse mit Hilfe von AMOS, SmartPLS und SPSS [An introduction into causal analysis with the help of AMOS, SmartPLS, and SPSS]. 2, erw. und korr: Aufl. Berlin: Springer Gabler; 2014:Springer-Lehrbuch.
26. Raykov T. Estimation of congeneric scale reliability using covariance structure analysis with nonlinear constraints. Br J Math Stat Psychol. 2001;54(2):315-323.

27. Hair JF. Multivariate Data Analysis: A Global Perspective. 7th ed. Upper Saddle River, NJ: Pearson; 2010.

28. Sapp M, Obiakor FE, Gregas AJ, Scholze S. Mahalanobis distance: A multivariate measure of effect in hypnosis research. Sleep Hypn. 2007;9(2):67-70.

29. Tabachnick BG, Fidell LS. Using Multivariate Statistics. Pearson New International Edition. 6th ed. Harlow: Essex: Pearson Education; 2014:Pearson custom library.

30. Nimon K, Henson RK, Gates MS. Revisiting Interpretation of Canonical Correlation Analysis: A Tutorial and Demonstration of Canonical Commonality Analysis. Multivariate Behav Res. 2010;45(4): 702-724.

31. Kim Y, Kim T-H, Ergün T. The instability of the Pearson correlation coefficient in the presence of coincidental outliers. Finance Res Lett. 2015;13:243-257.

32. Bortz J, Schuster C. Statistik für Human- und Sozialwissenschaftler: Extras online. Berlin: Heidelberg: Springer; 2010:Springer-Lehrbuch.

33. Soler JK, Yaman H, Esteva M, et al. Burnout in European family doctors: The EGPRN study. Fam Pract. 2008;25(4):245-265.

34. Stevens J. Applied multivariate statistics for the social sciences. 3rd ed., 7. print. Mahwah, NJ: Lawrence Erlbaum; 1996.

35. Cramer EM, Nicewander WA. Some Symmetric, invariant measures of multivariate association. Psychometrika. 1979;44(1):43-54.

36. Twellaar M, Winants Y, Houkes I. How healthy are Dutch general practitioners? Self-reported (mental) health among Dutch general practitioners. Eur J Gen Pract. 2008;14(1):4-9.

37. Yuguero O, Ramon Marsal J, Esquerda M, Vivanco L, Soler-González J. Association between low empathy and high burnout among primary care physicians and nurses in Lleida, Spain. Eur J Gen Pract. 2017;23(1):4-10.

38. Rottenfußer R. Viele Kassenärzte fühlen sich ausgebrannt [Many physicians are burned out. Dtsch Arztebl Ausg A. 1999;96:A610-613.

39. Lee YY, Medford ARL, Halim AS. Burnout in physicians. $J R$ Coll Physicians Edinb. 2015;45(2):104-107.

40. Kirkcaldy BD, Trimpop R, Cooper CL. Working hours, job stress, Work Satisfaction, and Accident Rates Among Medical Practitioners and Allied Personnel. Int J Stress Manag. 1997;4(2):79-87.

41. Shanafelt TD, Boone S, Tan L, et al. Burnout and satisfaction with work-life balance among US physicians relative to the general US population. Arch Intern Med. 2012;172(18):1377-1385.

42. Gutierrez-Zotes A, Labad J, Martorell L, et al. The revised Temperament and Character Inventory: Normative data by sex and age from a Spanish normal randomized sample. PeerJ. 2015;3:e1481.

43. Van Ham I, Verhoeven AA, Groenier KH, Groothoff JW, De Haan J. Job satisfaction among general practitioners: A systematic literature review. Eur J Gen Pract. 2006;12(4):174-180.

44. Sanchez-Piedra CA, Jaruseviciene L, Prado-Galbarro FJ, et al. Factors associated with professional satisfaction in primary care: Results from EUprimecare project. Eur J Gen Pract. 2017;23(1):114-120.

45. Körner M, Wirtz MA, Bengel J, Göritz AS. Relationship of organizational culture, teamwork and job satisfaction in interprofessional teams. BMC Health Serv Res. 2015;15:243.

46. Karsh BT, Beasley JW, Brown RL. Employed family physician satisfaction and commitment to their practice, work group, and health care organization. Health Serv Res. 2010;45(2):457-475.

47. Harmon-Jones E, Harmon-Jones C. Cognitive Dissonance Theory After 50 Years of Development. Zeitschrift für Sozialpsychologie. 2007;38(1):7-16. 


\section{Supplementary materials}

Table SI Factor loadings of the three-factor solution of the MBI in the confirmatory factor analysis

\begin{tabular}{|c|c|}
\hline & Factor loading \\
\hline \multicolumn{2}{|c|}{ Factor emotional exhaustion } \\
\hline Emotionally drained & 0.80 \\
\hline Used up & 0.68 \\
\hline Fatigue in the morning & 0.70 \\
\hline Stress & 0.72 \\
\hline Burned out & 0.69 \\
\hline Frustrated & 0.63 \\
\hline Working hard & 0.38 \\
\hline Working with people & 0.64 \\
\hline End of rope & 0.34 \\
\hline \multicolumn{2}{|c|}{ Factor depersonalization/loss of empathy } \\
\hline Impersonal & 0.66 \\
\hline Callous & 0.71 \\
\hline Hardening emotionally & 0.75 \\
\hline Don't care & 0.29 \\
\hline Blame & 0.28 \\
\hline \multicolumn{2}{|c|}{ Factor personal accomplishment } \\
\hline Can understand & 0.26 \\
\hline Deal effectively & 0.32 \\
\hline Positively influencing & 0.05 \\
\hline Energetic & 0.65 \\
\hline Relaxed atmosphere & 0.69 \\
\hline Feel exhilarated & 0.32 \\
\hline Accomplished & 0.73 \\
\hline Emotional problems & 0.46 \\
\hline
\end{tabular}

Notes: Copyright $\odot$ I 98I. MBI-HSS. Maslach C and Jackson SE. With permission from MBI: human services survey. All rights reserved in all media. Published by Mind Garden, Inc., www.mindgarden.com. Available from: https://www.mindgarden.com/3/4-mbi-human-services-survey\#horizontalTab2.' Updated with permission of the publisher. Abbreviation: MBI, Maslach Burnout Inventory.

Table S2 Factor loadings of the five-factor solution of the WSQ in the confirmatory factor analysis

\begin{tabular}{|l|l|}
\hline & $\begin{array}{l}\text { Factor } \\
\text { loading }\end{array}$ \\
\hline Factor: patient care & \\
Relations with patients & 0.83 \\
Autonomy in treating your patients & 0.78 \\
Autonomy in referring to a specialist & 0.54 \\
Quality of care you can provide & 0.65 \\
Factor: burden & \\
Workload & 0.77 \\
Time for family, friends, leisure & 0.65 \\
Work-related stress & 0.72 \\
Administrative burden & 0.55 \\
Factor: income-prestige & \\
Current income & 0.74 \\
Manner in which you are currently paid & 0.65 \\
Social status and respect & 0.40 \\
Factor: personal rewards & \\
Intellectual stimulation & 0.68 \\
Opportunity for continuing medical education & 0.66 \\
Enjoyment of work & 0.71 \\
Factor: professional relations & \\
Relations with peers & 0.63 \\
Relations with nonmedical staff & 0.76 \\
\hline
\end{tabular}

Abbreviation: WSQ, Work Satisfaction Questionnaire.
Table S3 Factor intercorrelations of factors of the WSQ in the confirmatory factor analysis

\begin{tabular}{|l|l|l|l|l|}
\hline & Burden & $\begin{array}{l}\text { Income- } \\
\text { prestige }\end{array}$ & $\begin{array}{l}\text { Personal } \\
\text { rewards }\end{array}$ & $\begin{array}{l}\text { Professional } \\
\text { relations }\end{array}$ \\
\hline $\begin{array}{l}\text { Patient } \\
\text { care }\end{array}$ & 0.18 & 0.31 & 0.64 & 0.72 \\
$\begin{array}{l}\text { Burden } \\
\text { Income- }\end{array}$ & & 0.51 & 0.32 & 0.46 \\
$\begin{array}{l}\text { prestige } \\
\text { Personal } \\
\text { rewards }\end{array}$ & & 0.33 & 0.44 \\
\hline
\end{tabular}

Abbreviation: WSQ, Work Satisfaction Questionnaire.

Table S4 Standardized canonical coefficients and structure correlations of the first criterion canonical variate

\begin{tabular}{|l|l|l|}
\hline $\begin{array}{l}\text { Criterion } \\
\text { canonical variate }\end{array}$ & $\begin{array}{l}\text { Standardized } \\
\text { canonical coefficients }\end{array}$ & $\begin{array}{l}\text { Structure } \\
\text { correlations }\end{array}$ \\
\hline Emotional exhaustion & 1.10 & 0.91 \\
Personal & -0.25 & -0.36 \\
accomplishment & & 0.20 \\
Depersonalization & -0.47 & \\
\hline
\end{tabular}


Table S5 Standardized canonical coefficients and structure correlations of the second criterion canonical variate

\begin{tabular}{|l|l|l|}
\hline $\begin{array}{l}\text { Criterion } \\
\text { canonical variate }\end{array}$ & $\begin{array}{l}\text { Standardized } \\
\text { canonical coefficients }\end{array}$ & $\begin{array}{l}\text { Structure } \\
\text { correlations }\end{array}$ \\
\hline $\begin{array}{l}\text { Emotional exhaustion } \\
\text { Personal }\end{array}$ & -0.18 & 0.37 \\
accomplishment & 0.17 & -0.20 \\
Depersonalization & 1.13 & 0.97 \\
\hline
\end{tabular}

\section{Reference}

1. Maslach C and Jackson SE. MBI: human services survey. Available from: https://www.mindgarden.com/314-mbi-human-servicessurvey\#horizontalTab2. Accessed October 30, 2018.

\section{Publish your work in this journal}

Psychology Research and Behavior Management is an international, peerreviewed, open access journal focusing on the science of psychology and its application in behavior management to develop improved outcomes in the clinical, educational, sports and business arenas. Specific topics covered in the journal include: Neuroscience, memory and decision making; Behavior

modification and management; Clinical applications; Business and sports performance management; Social and developmental studies; Animal studies. The manuscript management system is completely online and includes a very quick and fair peer-review system, which is all easy to use. Visit http://www. dovepress.com/testimonials.php to read real quotes from published authors. 